\title{
INFLUÊNCIA DOS ESPECIALISTAS NO CONTEÚ- DO DEFINICIONAL DOS DICIONÁRIOS ESPE- CIALIZADOS: O CASO DO VOCABULÁRIO MULTILÍNGUE DE DERMATOLOGIA - VMD
}

Lídia Almeida Barros ${ }^{1}$

\begin{abstract}
RESUMO: Percebemos, ao longo desta pesquisa. que as diferentes visóes dos especialistas da área em estudo (no caso, a Dermatologia) sobre o objeto descrito acabam determinando a organizaçāo, por parte do terminólogo, do sistema conceptual e, consequentemente, o conteúdo dos enunciados definicionais dos verbetes de um dicionário. Neste artigo. abordaremos um problema bastante comum com o qual o terminólogo se depara durante a elaboraçāo de dicionários técnicos e científicos: as diferentes visões que os especialistas da área têm do objeto descrito.
\end{abstract}

Palavras-chave: Terminologia, Definiçōes, Sistema conceptual, Dermatologia

\section{INTRODUÇÃO}

Os dados aqui apresentados constituem parte dos resultados obtidos em nossa pesquisa no âmbito do projeto Vocabulário Multilingue de Dermatologia-VMD, desenvolvido no Instituto de Biociências, Letras e Ciências Exatas-IBILCE de São José do Rio Preto. Nesse dicionário, os termos estão organizados em uma relação hierárquica de sentido e as unidades terminológicas são dispostas em um sistema estruturado (sistema conceptual ou árvore do domínio). As definições foram elaboradas levando em conta a posição que cada termo ocupa nesse sistema.

1 Professora do IBILCE - UNESP. campus de Sāo José do Rio Preto 
Percebemos, ao longo da pesquisa, que as diferentes visões dos especialistas da área de especialidade em estudo (no caso, a Dermatologia) sobre o objeto descrito acabam determinando a organização, por parte do terminólogo, do sistema conceptual e, consequentemente, o conteúdo dos enunciados definicionais dos verbetes do dicionário.

Pudemos vivenciar essa questão quando uma de nossas atribuições no projeto foi a de proceder à reestruturação do campo conceptual "Fotodermatoses" e de reformular as definições de alguns desses termos. Nosso corpus constituiu-se de três tratados de Dermatologia, obras de referência renomadas na área, a saber: Azulay \& Azulay (1999), Sampaio \& Rivitti (2001) e Bechelli \& Curban (1988).

Para resgatar os contextos que viriam fornecer dados para a homogeneização desse campo conceptual em nosso dicionário e para a redação das definições, procedemos a um estudo aprofundado dos capítulos das três obras relativos a "fotodermatoses" Constatamos que a terminologia adotada pelos autores coincidia em determinados casos, mas diferia muito em outros. A maior diferença demonstrou-se, entretanto, no que concerne à classificação dada a essas doenças da pele (dermatoses). Observamos que os autores possuíam visões diferentes das doenças e que esse fenomeno extralinguístico imprimia obrigatoriamente consequências no plano linguistico. De fato, classificaçōes distintas provocam organização diferente dos termos no sistema conceptual e conduzem a uma descrição distinta dos mesmos. O terminológo é, portanto, confrontado a dados diversos para a redação das definições.

Para que se possa compreender melhor a questão aqui abordada, no Item 2 deste artigo discorreremos sobre a importância do conceito e do sistema conceptual no processo de elaboração de um dicionário técnico ou científico. No Item 3 , discutiremos o papel do especialista e do terminólogo na elaboração de obras terminográficas. No Item 4, apresentare- 
mos alguns aspectos metodológicos de nosso trabalho, no qual exporemos algumas características dos tratados que compuseram nosso corpus de referência. No Item 5, utilizando exemplos do subcampo conceptual "Fotodermatoses" do VMD, apresentaremos as diferentes visões dos especialistas sobre esse campo conceptual e, no Item 6, daremos exemplos de expressões das diferentes visões dos especialistas nas definições. No Item 7 enfim, faremos algumas considerações finais.

\section{Conceito e sistema conceptual}

O conceito pode ser definido como uma "unidade de conhecimento constituído por abstração com base em traços ou propriedades comuns a uma classe de objetos, de relações ou de entidades" (Pavel; Nolet, 2002:105), ou seja, um conceito é a representação mental que fazemos das caracteristicas mais importantes de um objeto ou de um grupo de objetos. Assim, o conceito de "fotodermatose" é a idéia que temos desse objeto da realidade extralinguística (uma dermatose), de seus sintomas, causas, e, sobretudo, das características que diferenciam uma fotodermatose de outra doença ou que, ainda, distinguem os diversos tipos de fotodermatoses.

Um conceito pode ser identificado, distinto e descrito por meio dos traços conceptuais, ou, de acordo com a linha teórica de Wuster, por meio de caracteristicas, isto é, de "representações mentais de uma propriedade de um objeto e que serve para delimitar seu conceito" (ISO 1087 1990:2).

Os termos e os conceitos são estudados em contexto, ou seja, no âmbito de "um enunciado que exprime uma idéia completa, no qual o termo estudado encontra-se atualizado" (Dubuc, 1985:62). Os traços conceptuais são identificados por meio dos chamados descritores, que são os elementos contidos no texto que revelam um conceito.

Uma das principais atividades do trabalho terminológico, quando em processo de elaboração de obras terminográficas, 
consiste na sistematização e na representação dos conceitos em um sistema conceptual. Por este último entendemos "o conjunto estruturado de conceitos tendo por base as relações estabelecidas entre eles e no qual cada conceito é determinado pela posição que ocupa nesse conjunto" (ISO 1087 1990:6). De acordo com Maria Teresa Cabré (1993), um conceito adquire seu valor dentro de um sistema conceptual.

Embora muitos terminólogos não adotem em sua metodologia de pesquisa e de elaboraçāo de dicionários a organizaçāo sistemática dos termos do domínio, esse procedimento é, a nosso ver, de grande importância, possuindo expressão na escolha da nomenclatura, no tratamento dos dados, na determinação dos critérios de funcionamento do sistema de remissivas, no aprofundamento de uma dada pesquisa terminológica, entre outros aspectos da elaboração de obras terminográficas (Barros, 2004:118-119).

O sistema conceptual organiza-se em campos conceptuais, entendidos como "conjuntos de conceitos que mantêm entre si relações temáticas e que podem ser agrupados em torno de um conceito-chave" (ISO 1087 1990:6). Este, por sua vez, é entendido como um "conceito fundamental em torno do qual pode ser agrupado um conjunto de conceitos que com ele estabelece relações hierárquicas ou não hierárquicas" (ISO 1087 1990:3). As relaçōes hierárquicas caracterizam-se pela divisão de um conceito superordenado em conceitos subordinados, resultando na formação de um ou vários niveis.

Os principais conceitos não hierárquicos são: a) os que mantêm relaçōes sequenciais, nas quais há dependência entre os conceitos referentes a objetos que apresentam uma proximidade espacial ou temporal, b) os que mantêm relações pragmáticas, nas quais os conceitos se ligam com base em relaçōes temáticas.

Há dois tipos fundamentais de relações hierárquicas: a) relação partitiva, em que o hiperônimo representa linguística 
e conceptualmente um objeto considerado como um todo e os hipônimos, as suas partes; b) relação genérica, baseada na identidade parcial da compreensão dos conceitos considerados específicos. Os conceitos mais genéricos (hiperônimos) possuem maior extensão semântica, enquanto que os específicos (hipônimos) apresentam maior compreensão. Entendese por extensão a classe das entidades às quais se aplicam ou se referem os termos em questão, enquanto que a compreensão é o conjunto de atributos que caracterizam toda entidade designada pelo termo. Extensão e compreensão são inversamente proporcionais.

Em nosso dicionário, as relações estabelecidas entre os conceitos são fundamentalmente do tipo hierárquico genérico-especificas; a organização dos termos adotada foi a forma de lista sistemática, pois esse tipo de estruturação evidencia as relaçōes hiperonimicas, hiponimicas e co-hiponimicas entre os termos pela diferença de tabulação e pela especificidade do simbolo de classificação. Para termos uma idéia mais precisa da configuração do sistema conceptual do VMD, apresentamos abaixo um trecho do campo conceptual "fotodermatoses" que será tratado em detalhes mais adiante:

\subsection{2. fotodermatose}

4.32.1. fotodermatose tóxica primária

4.32.1.1. fotodermatose tóxica primária precoce

4.32.1.1.1. fotodermatose tóxica primária precoce pigmentar

4.32.1.1.1.1. fotodermatose tóxica primária precoce pigmentar imediata, bronzeamento imediato, fenômeno de Meirowsky

O símbolo de classificação, ou seja, o código numérico que se apresenta diante dos termos, indica a posição dos mesmos na escala hierárquica de sentido do sistema 
estruturado, evidenciando, assim, a relação hiperônimo/ hipônimo.

Essas relações de significação mantidas entre os termos são muito importantes quando da elaboração de dicionários, pois delas depende a organização da macro e microestruturas e do sistema de remissivas. Esse aspecto é de grande relevância para a questão que analisamos neste artigo, isto é, a visão do objeto (representado linguística e conceptualmente pelo termo) como determinante da compreensão, delimitação e descrição dos conceitos em uma obra terminográfica. De fato, Cabré explica que "a estruturação de um campo conceptual reflete uma determinada visão cultural e científica da realidade e, nesse sentido, permite diferentes abordagens cientificas de um mesmo objeto de base e diferentes abordagens culturais de uma mesma realidade" (1993:208).

O especialista do domínio exerce, efetivamente, grande influência sobre a organização do sistema conceptual, sobre a descrição dos termos nos enunciados definicionais e sobre a estruturaçāo do dicionário como um todo, como procuraremos demonstrar a seguir.

\section{O PAPEL DO ESPECIALISTA E do TERMinÓlogo NA ELABORAÇĀO DE OBRAS TERMINOGRÁFICAS}

Ao elaborar dicionários de áreas técnicas e científicas, o terminólogo deve estar sempre atento às fontes utilizadas, visto que, de acordo com Guy Rondeau, "a qualidade do trabalho sobre os termos depende da qualidade das fontes utilizadas" (1984:85). Na maior parte das vezes, essas fontes são escritas, mas vale lembrar que são de grande importância também as fontes orais, ou seja, a opinião dos especialistas que assessoram os terminólogos em seu trabalho, e, não esqueçamos, a opinião dos próprios terminólogos (idem, ibidem). São os especialistas que atestam todas as formas linguisticas de um termo, confirmam o uso de cada unidade terminológica 
a partir das hipóteses levantadas pelo terminólogo com base nas fontes de referência (Rondeau, 1984:101).

Em casos de sinonímia, somente esses profissionais podem julgar o valor da relação que se estabelece entre denominação e conceito. A presença do especialista se faz importante também em terminologia comparada, visto que, se o mesmo for bilíngue ou tiver grande conhecimento da língua estrangeira, poderá verificar as equivalências dos termos em duas ou mais linguas (Rondeau, 1984:102).

A opinião de um especialista ainda é indispensável na criação neonímica e na difusão dos termos normalizados, já que ele constitui um testemunho da aceitabilidade de tal ou tal termo por seus colegas (idem, ibidem).

$\mathrm{Na}$ formulação de definições ou na escolha entre várias definições, o terminólogo deve sempre contar com a ajuda de especialistas. Sendo assim, o conteúdo do enunciado definicional é determinado não só pelo trabalho de descrição feito pelo terminólogo, mas também pela visão que os especialistas da área têm do objeto descrito.

Como se pode ver, as funções do terminólogo e do especialista complementam-se. De um lado, o especialista emite sua opinião e esclarece as dúvidas do terminólogo; de outro, este último não se caracteriza como um simples executor das sugestōes do assessor técnico. De fato, o papel do terminólogo vai muito além disso, sendo este um ser intelectualizado que conhece de modo considerável o domínio (embora não tanto quanto o especialista) e que tem como tarefa fundamental compatibilizar dados provenientes de obras - no plural - sobre a matéria escrita por autoridades no assunto. Nesse sentido, o terminólogo passa a ter uma visão do domínio que pode - ou não - coincidir totalmente com a visão do especialista que dá assessoria técnica ao projeto em desenvolvimento.

Vale lembrar que, antes da árvore do dominio e das definições elaboradas pelo terminólogo chegarem às mãos do especialista (assessor técnico) para verificação final, essas 
sofreram a influência das visões dos especialistas autores das obras de referência que serviram de córpus para a extração dos dados sobre os termos do domínio estudado.

É exatamente sobre esse tipo de influência que trataremos no Item seguinte. Com base em exemplos do subcampo conceptual "Fotodermatoses" mostraremos como os especialistas do dominio (enquanto assessores - fontes orais - ou enquanto autores de obras de referência) e os terminólogos acabam impondo certas caracteristicas ao trabalho terminológico.

\section{Aspectos METOdológicos do TRABALHO DE ANÁlise}

Para organizarmos o subcampo conceptual "Fotodermatoses" no VMD, estudamos três importantes Tratados de Dermatologia. Cada um deles apresentava a visão de grandes especialistas, a saber: Rubem David Azulay e David Rubem Azulay, professores renomados na UFRJ; Sebastiāo A P. Sampaio e Evandro A. Rivitti, do Hospital das Clínicas e da Faculdade de Medicina de São Paulo; e Luiz Marino Bechelli e Guilherme Villela Curban, autoridades em Dermatologia da Universidade de São Paulo, campus de Ribeirão Preto e de São Paulo.

Durante o estudo dessas três obras, notamos que cada autor emprega uma terminologia científica própria e classifica as doenças de forma diferente. Esse problema é bastante comum nos domínios de especialidade. No entanto, o terminólogo pode chegar a uma conclusão após a análise de cada obra e após a comparação das visōes dos autores.

Em nossa pesquisa, pudemos notar que Azulay \& Azulay é a única das três obras que organizou os termos que designam os diferentes tipos de fotodermatose de forma similar ao sistema conceptual elaborado pelos terminólogos, utilizando inclusive, códigos numéricos.

Sampaio \& Rivitti, por sua vez, dedicam um capitulo exclusivamente às fotodermatoses, porém não organizam os 
termos no mesmo estilo de Azulay \& Azulay. Contudo, pela forma e pela sequência como os autores apresentam essas dermatoses, é possivel estabelecermos um sistema conceptual coerente.

Bechelli \& Curban não empregam, em nenhum trecho de sua obra, o termo "fotodermatoses" Ao se referirem a esse grupo de doenças, falam em "afecçōes ou reações produzidas pela radiação solar" Os autores apenas citam algumas dermatoses sem, no entanto, defini-las (ao menos dentro do capitulo que trata das "afecçōes ou reaçōes produzidas pela radiação solar"). As únicas doenças definidas nesse capítulo são: eritema solar, também chamado de dermatite solar aguda e conhecido como queimadura solar; fotodermatites, provocadas por substâncias quimicas (dermatites fotoquímicas) ou por vegetais (fitofotodermatites); urticária solar; prurigo solar, também denominado prurigo de verāo ou estival ou, ainda, erupção polimorfa actínica ou eczema solar. Os autores ainda discorrem rapidamente sobre envelhecimento antecipado da pele.

Ao contrário dos outros autores, Bechelli \& Curban não apresentam as doenças de modo hierárquico (do mais genérico ao mais específico) e não descrevem a maior parte dessas dermatoses nesse capítulo. Muitas das doenças que Azulay e Sampaio tratam e definem em "fotodermatoses" Bechelli \& Curban apresentam em outro capítulo de sua obra. Por essa razão, a obra de Bechelli \& Curban não pôde ser por nós utilizada como referência maior neste caso específico de estruturação do campo conceptual "fotodermatose" Por outro lado, sua obra contribuiu para o levantamento de contextos utilizados na elaboração das definições.

5. FOTODERMATOSES: DIFERENTES VISÕES DOS ESPECIALISTAS

Pelo exposto acima, percebe-se que Bechelli \& Curban. comparado aos outros Tratados que compuseram nosso corpus, é a obra que menos fornece informaçōes sobre as 
fotodermatoses. Assim, neste artigo, restringimo-nos às visões de Azulay \& Azulay e Sampaio \& Rivitti.

Com base nos dados obtidos nas obras desses especialistas, pudemos organizar o quadro comparativo abaixo:

\begin{tabular}{|c|c|}
\hline Azulay \& Azulay & Sampaio \& Rivitti \\
\hline Fotodermatose & \begin{tabular}{|c|} 
Fotodermatose \\
\end{tabular} \\
\hline $\begin{array}{l}\text { I. Fotodermatoses tóxicas } \\
\text { primárias }\end{array}$ & I. Fotodermatoses por irritação primária \\
\hline $\begin{array}{l}\text { 1.1. Fotodermatoses tóxicas } \\
\text { primárias precoces }\end{array}$ & $\begin{array}{l}\text { I. 1. Fotodermatoses por irritaçāo primária } \\
\text { imediata }\end{array}$ \\
\hline $\begin{array}{l}\text { I. l. l. Fotodermatoses tóxicas } \\
\text { primárias precoces eritematosas: } \\
\text { queimadura }\end{array}$ & I.1.1. Eritema ou queimadura solar \\
\hline $\begin{array}{l}\text { I. 1.2. Fotodermatoses tóxicas } \\
\text { primárias precoces pigmentar }\end{array}$ & I.1.2. Pigmentação solar \\
\hline $\begin{array}{l}\text { I. 1.2.1. Bronzeamento imediato, } \\
\text { Fenōmeno de Meirowsky }\end{array}$ & $\begin{array}{c}\text { I. 1.2.1. Pigmentaçāo imediata, } \\
\text { bronzeamento pigmentar imediato, } \\
\text { Fenómeno de Meirowsky }\end{array}$ \\
\hline I.1.2.2. Bronzeamento tardio & $\begin{array}{l}\text { I. 1.2.2. Pigmentaçāo tardia, bronzeamento } \\
\text { pigmentar tardio }\end{array}$ \\
\hline I.1.3. Espessamento epidérmico & (n...... \\
\hline 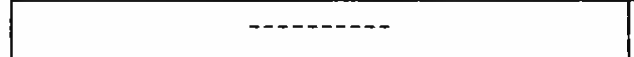 & I.1.3. Miliária solar \\
\hline $\begin{array}{l}\text { I.2. Fotodermatose tóxica primária } \\
\text { tardia }\end{array}$ & $\begin{array}{l}\text { I.2. Fotodermatose por irritação primària } \\
\text { tardia, fotodermatose por irritaçāo } \\
\text { cumulativa }\end{array}$ \\
\hline $\begin{array}{c}\text { 1.2.1. Dermatose elastótica } \\
\text { actinica }\end{array}$ & \\
\hline - & I.2.1. Pele fotolesada ou fotoenvelhecida \\
\hline I.2.1.1. Elastoma difuso & - \\
\hline - -........-- & I.2.2. Melanose solar \\
\hline I.2.1.2. Pele romboidal & - \\
\hline - & I.2.3. Queratose solar \\
\hline I.2.1.3. Pele citreinica & 1.2.4. Elastose solar, peau citrine \\
\hline & I.2.4.1. Cútis romboidal \\
\hline & I.2.4.2. Elastoma difuso \\
\hline $\begin{array}{l}\text { I.2.1.4. Elastoidose cistica e } \\
\text { comedönica (Favre-Racouchot) }\end{array}$ & $\begin{array}{c}\text { I.2.4.3. Elastose com cistos e comedões } \\
\text { (Favre-Racouchot) }\end{array}$ \\
\hline $\begin{array}{c}\text { I.2.1.5. Nódulos elastóticos das } \\
\text { orelhas }\end{array}$ & $\begin{array}{l}\text { I.2.4.4. Nódulos elastóticos das orelhas (da } \\
\text { anti-hélix) }\end{array}$ \\
\hline 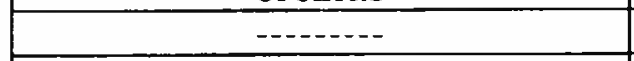 & I.2.5. Poiquilodermia solar \\
\hline $\begin{array}{l}\text { 1.2.1.6. Ceratodermia marginal } \\
\text { das palmas }\end{array}$ & \\
\hline------- & 1.2.6. Leucodermia gotada solar \\
\hline I.2.1.7. Granuloma actínico & - n \\
\hline - & I.2.7. Milio colóide \\
\hline
\end{tabular}




\begin{tabular}{|c|c|}
\hline $\begin{array}{l}\text { I.2.1.8. Dermatite verrucosa } \\
\text { elastótica solar }\end{array}$ & ------- \\
\hline - & I.2.8. Xerodermia solar \\
\hline 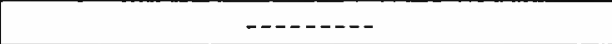 & I.2.9. Neoplasias malignas \\
\hline I.2.2. Câncer cutâneo & $-\cdots$ \\
\hline $\begin{array}{l}\text { II. Fotodermatoses induzidas por } \\
\text { substancias quimicas }\end{array}$ & $\begin{array}{l}\text { II. Fotodermatoses por sensibilizaçāo, } \\
\text { fotodermatites }\end{array}$ \\
\hline II. 1. Fototóxicas & II. 1. Fototoxidade \\
\hline II.2. Fotoalérgicas & II.2. Fotoalergia \\
\hline III. Fotodermatoses idiopáticas & III. Fotodermatoses idiopáticas \\
\hline $\begin{array}{l}\text { III. 1. Erupçāo actinica polimorfa, } \\
\text { erupçāo polimorfa luminica }\end{array}$ & III.1. Erupçāo polimorfa à luz \\
\hline - & III. 1.1. Prurigo estival \\
\hline III.2. Urticária solar & III.2. Urticária solar \\
\hline III.3. Reticulóide actínico & III.3. Prurigo actinico \\
\hline III.4. Hidroa vaciniforme & III.4. Hidroa vaciniforme \\
\hline IV. Grupo miscelânea & - \\
\hline $\begin{array}{l}\text { IV.1. Poiquilodermia actinica } \\
\text { (Civatte). }\end{array}$ & - - - \\
\hline $\begin{array}{l}\text { IV.2. Dermatose coloidal actínica } \\
\text { (pseudomilio colóide). }\end{array}$ & 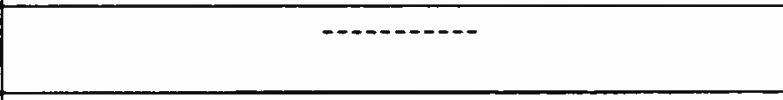 \\
\hline IV.3. Queilite actinica. & -............... \\
\hline IV.4. Lentigo actinico. & (................ \\
\hline IV.5. Ceratose actínica. & 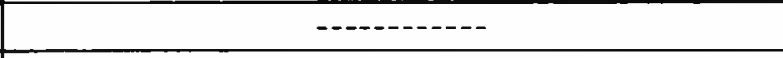 \\
\hline $\begin{array}{l}\text { IV.6. Cânceres cutâneos } \\
\text { (epiteliomas e melanomas). }\end{array}$ & ---------- \\
\hline IV.7. Púrpura senil (Bateman) & 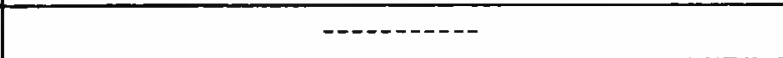 \\
\hline $\begin{array}{l}\text { IV.8. Pseudocicatrizes estelares } \\
\text { (Colomb e cols.). }\end{array}$ & (n.......... \\
\hline IV.9. Hiperplasia sebácea & 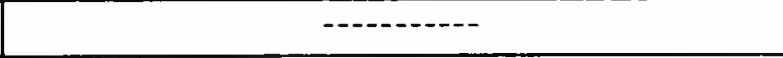 \\
\hline $\begin{array}{l}\text { IV.10. Miliäria solaris (Padilha- } \\
\text { Gonçalves). }\end{array}$ & -......- \\
\hline IV.11. Outras entidades. & -..--- \\
\hline 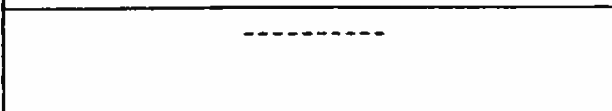 & $\begin{array}{l}\text { IV. Fotodermatoses em doenças genéticas e } \\
\text { metabólicas }\end{array}$ \\
\hline ---------- & IV.1. Sindrome de Hartnup \\
\hline -------- & IV.2. Queratose folicular, Doença de Darier \\
\hline---- & $\begin{array}{l}\text { IV.3. Eritema telangiectásico congénito, } \\
\text { Sindrome de Bloom }\end{array}$ \\
\hline
\end{tabular}




\begin{tabular}{|c|c|}
\hline --------- & IV.4. Xeroderma pigmentoso \\
\hline$\cdots+\cdots$ & IV.5. Pelagra \\
\hline 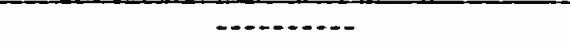 & IV.6. Porfiria \\
\hline $\begin{array}{l}\text { V. Doenças precipitadas ou } \\
\text { agravadas pelas radiaçōes } \\
\text { solares }\end{array}$ & 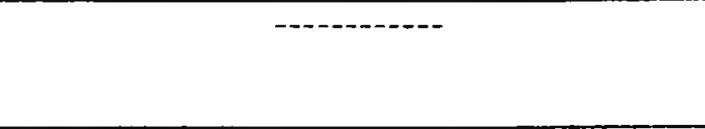 \\
\hline $\begin{array}{l}\text { V1.Hereditárias: síndromes de } \\
\text { Hartnup, Cockayne e de Bloom, } \\
\text { Doença de Darier, xeroderma } \\
\text { pigmentoso, porfirias etc. }\end{array}$ & $-\cdots-\cdots$ \\
\hline $\begin{array}{l}\text { V.2.Adquiridas: lúpus } \\
\text { eritematoso, cloasma, porfiria } \\
\text { cutānea tarda, eczema de } \\
\text { contato, pênfigo vulgar etc. }\end{array}$ & $-\cdots$ \\
\hline - & V. Dermatoses agravadas pela luz solar \\
\hline ----------- & V.1. Pitiriase alba \\
\hline -................. & V.2. Pitiriase versicolor \\
\hline ---------- & V.3. Lúpus eritematoso \\
\hline 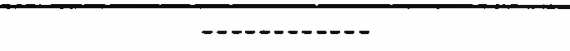 & V.4. Herpes simples \\
\hline
\end{tabular}

Analisando esse quadro comparativo, nota-se que o termo I.1.3. Espessamento epidérmico, presente em Azulay \& Azulay. não apresenta correspondente em Sampaio \& Rivitti. Estes autores não tratam do espessamento epidérmico como uma doença isolada, mas o apresentam como sintoma de outras doenças, como podemos constatar nos excertos a seguir:

QUERATOSE: Espessamento da pele, duro, inelástico, amarelado e de superficie eventualmente áspera, por aumento da camada córnea.

LIQUUENIFICAÇÃO: Espessamento da pele com acentuação dos sulcos e da cor própria, com aspecto quadriculado. É devido, principalmente, ao aumento da camada malpighiana.

EDEMA: Aumento de espessura, depressivel, com a cor própria da pele ou rósea-branca, por extravasamento de plasma na derme e/ou hipoderme (Sampaio, 2001:73).

O quadro nos mostra também que vários termos apresentados em uma obra não encontram correspondentes na 
outra, tais como: dermatose elastótica actínica, pele fotolesada ou fotoenvelhecida, queratose solar, poiquilodermia solar ceratodermia marginal das palmas, leucodermia gotada solar. granuloma actinico, dermatite verrucosa elastótica solar xerodermia solar, neoplasias malignas e câncer cutâneo.

Outro fato que nos chamou a atenção foi o de que o termo I.1.3. Miliária solar (em Sampaio \& Rivitti), cujo hiperônimo é "fotodermatoses por irritação primária imediata" aparece em Azulay \& Azulay com o simbolo de classificação IV.10, pertencendo, assim, ao chamado "Grupo miscelânea" Desse modo, podemos perceber que a definição de miliária solar para cada autor é diferente.

Os termos cútis romboidal, elastoma difuso, elastoidose nodular a cistos e comedōes de Faure-Racouchot e nódulos elastóticos das orelhas (da ante-hé-lix) são hipônimos de elastose solar em Sampaio \& Rivitti, enquanto que em Azulay \& Azulay seus correspondentes são hipônimos de dermatose elastótica actínica.

Erupçāo polimorfa à luz em Sampaio \& Rivitti tem como hipônimo prurigo estival. Já o correspondente em Azulay \& Azulay. erupção actínica polimorfa/erupçāo polimorfa luminica, não apresenta nenhum hipônimo.

Em Sampaio \& Rivitti não existe um subcampo conceptual com as características do IV Grupo miscelânea de Azulay \& Azulay. no qual sāo classificadas algumas doenças que, na opinião desses últimos autores, não se encaixam em nenhum dos demais subcampos.

Observando algumas doenças que Azulay \& Azulay apresentam no subcampo $V$. Doenças precipitadas ou agravadas pelas radiaçōes solares, tais como sindromes de Hartnup, Cockayne e de Bloom, Doença de Darier xeroderma pigmentoso, porfirias e lúpus eritematoso, pode-se dizer que tal subcampo é uma mescla dos subcampos $I V$. Fotodermatoses em doenças genéticas e metabólicas e $V$. Dermatoses agravadas pela luz solar de Sampaio \& Rivitti. 
Os sistemas conceptuais acima, que organizamos de forma comparativa, permitem-nos notar que há correspondência entre vários termos empregados pelos autores das duas obras, porém, em outros casos, as terminologias e a organização conceptual são diferentes.

Com base nos dados acima expostos, nota-se que há algumas diferenças de classificação das "fotodermatoses" na visão de cada autor, o que, consequentemente, imprime caracteristicas ao conteúdo definicional dos termos que designam essas dermatoses, como exporemos a seguir.

\section{EXPRESSÃO DAS DIFERENTES VISÕES NA DEFINIÇĀO}

Apresentaremos abaixo de que modo as diferentes visōes dos autores se expressam na definição, tomando como exemplo os termos miliária solar e prurigo estival.

Como mencionado no capitulo anterior, Sampaio classifica a miliária solar como uma "fotodermatose por irritação primária imediata” enquanto que Azulay a insere no Grupo miscelânea. Consequentemente, a definição dessa dermatose para cada autor será diferente. Abaixo transpomos o trecho em que Sampaio define o termo miliária solar:

\begin{tabular}{|l|}
\hline Sampaio \\
\hline Miliária Solar. Caracteriza-se pelo aparecimento de \\
pequenas pápulas, encimadas eventualmente por \\
vesículas puntiformes ou crosticulas serosas, hemáticas \\
ou sero-hemáticas. Surgem alguns dias após exposição \\
solar intensa, no tórax, principalmente na porção \\
superior, abdome e membros superiores. Nāo aparece \\
nas áreas cobertas pela roupa de banho. \\
A pele está eritematosa ou pigmentada (eritema ou \\
pigmentação solar) ou seca e descamativa (xerodermia \\
solar). Há prurido moderado e sensação de picadas. \\
Clinicamente, deve ser distinguida da miliária (Capitulo \\
29) na qual, pela ação do calor, surgem lesōes \\
vesiculosas ou vesicopapulosas, e da acne solar, em que \\
as lesōes são pápulas foliculares (Capitulo 21) e com a \\
qual pode, eventualmente, estar associada (p.633-634). \\
\hline
\end{tabular}


Assinalamos em negrito as principais caracteristicas dessa dermatose na visão de Sampaio. Nota-se, ainda, que o autor atenta para o fato de que, no capítulo 29 de sua obra, é descrita a miliária, que não deve ser confundida com miliária solar. Vejamos a definiçāo de miliária na visāo desse autor:

\begin{tabular}{l} 
Miliária \\
\hline A miliảria é erupção causada pela obstrução dos dutos \\
sudoriparos com ruptura e subsequente extravasamento \\
de suor na pele. Há três formas de miliária: miliária \\
cristalina ou sudamina, na qual a obstrução e ruptura \\
ocorrem dentro da camada córnea; miliária rubra \\
(brotoeja), em que a obstrução e ruptura ocorrem na \\
camada malpighiana; e a miliảria profunda, em que a \\
obstrução e ruptura ocorrem na junçāo dermo- \\
epidérmica (p.31l).
\end{tabular}

Embora Azulay classifique miliária solar como uma dermatose do grupo miscelânea, não encontramos em sua obra uma definição para tal termo. Apenas localizamos a definição do termo miliária descrito no capítulo sobre afecçōes das glândulas sudoriparas écrinas, como veremos abaixo:

\section{Azulay}

Miliária. É mais comum na criança e caracteriza-se por erupção sudoral aguda vesiculosa, disseminada pelo tronco $e$, às vezes, membros, em consequência de superaquecimento ou, ocasionalmente, por exercicio fisico, exposiçāo solar etc. Atribui-se à produção excessiva de suor que nāo consegue ser totalmente excretado. Há três formas clinicas: a miliária cristalina (sudamina) è assintomática, e as vesiculas são brancocristalinas e subcórneas, porque a obstruçāo ocorre ao nivel da córnea; na miliária rubra (brotoeja), as vesiculas assestam-se em pele eritematosa devido ao fato de a obstrução ocorrer no nivel da camada de Malpighi (as vesiculas são intra-epidérmicas e espongióticas); há prurido e sensaçāo de picadura; na miliária profunda, as vesiculas assestam-se sobre pápulas eritematosas porque a obstruçāo se faz no nivel da junçāo dermoepidérmica; o suor provoca irritaçāo secundária estafilocócica, levando a um quadro de periporite (ver piodermites). A evoluçāo natural observa-se com reparação integral em uma a duas semanas. A terapéutica consiste em emulsão de calamina (formulário); o ar condicionado é preventivo. (p.439) 
Vimos, então, que Sampaio distingue a miliária (causada pela obstrução dos dutos sudoriparos) da miliária solar (que surge alguns dias após exposição solar intensa). Já Azulay, apesar de citar o termo miliaria solaris no capítulo das Fotodermatoses, define apenas miliária, semelhante à miliária de Sampaio.

No VMD, com base nos dados fornecidos por essas obras, optamos por classificar o termo miliária solaris como uma fotodermatose. Nossa definiçāo assemelha-se à definição de Sampaio, visto que Azulay não nos forneceu muitas características sobre essa dermatose além do fato de classificá-la no Grupo miscelânea. Vejamos abaixo a definição desse termo no VMD:

\begin{tabular}{|l|}
\hline VMD \\
\hline miliaria solaris: s f fotodermatose causada pela \\
exposiçāo intensa ao sol. Surgem pequenas pápulas \\
encimadas eventualmente por vesiculas puntiformes ou \\
crosticulas serosas, hemáticas ou sero-hemáticas. \\
Caracteriza-se pela pele seca e descamativa, ou seja, \\
xerodermia solar, pigmentação solar e eritema. Além de \\
ter prurido moderado, o paciente tem sensaçōes de \\
picadas. E importante distinguir a miliaria solaris da \\
miliária e da acne solar, já que na primeira a ação do \\
calor faz aparecer lesōes vesicobolhosas ou \\
vesicopapulosas e, na segunda, surgem pápulas \\
foliculares, a que eventualmente pode estar relacionada. \\
Localiza-se no tórax, principalmente na porção superior, \\
abdomem e membros superiores, e não atinge as áreas \\
que são cobertas por roupas de banho. Outras \\
Designaçōes: \\
\hline
\end{tabular}

A seguir apresentamos outro exemplo em que as diferenças de visão entre os autores dos compêndios de Dermatologia imprimiram consequências ao conteúdo definicional no VMD. Trata-se dos termos prurigo estival ou de verão (Sampaio) e prurigo estival ou de Hutchinson (Azulay). A definição desses termos segue adiante: 


\begin{tabular}{l}
\hline Sampaio \\
\hline Prurigo estival ou de verāo. É considerado como uma \\
forma de erupção polimorfa à luz. Clinicamente, \\
ocorrem pápulas e sero-pápulas, róseas ou eritematosas, \\
duras, com superfície achatada. Atinge preferencialmente \\
o dorso das mãos e pernas. A liquenificação é comum. Na \\
face, surgem, com frequēncia, lesōes escoriadas e \\
pápulas ligeiramente amareladas que lembram a porfiria \\
eritropoiética. Ocorrem também lesōes nas áreas \\
cobertas, principalmente nas nádegas. É mais frequente \\
em jovens na primeira década de vida, melhorando no \\
inverno. História familiar é positiva em metade dos \\
casos. A resposta às radiaçōes monocromáticas em foto- \\
teste no espectro do UVB são normais em 50\% dos \\
doentes. A terapia è a indicada na erupção polimorfa à \\
luz. (p.640)
\end{tabular}

Sampaio classifica a dermatose prurigo estival como uma erupção polimorfa à luz, ou seja, o termo prurigo estival carrega todo o conteúdo semântico de erupção polimorfa à luz, além de suas características específicas. Abaixo veremos a definição de prurigo estival para Azulay:

\begin{tabular}{|l|}
\hline Azulay \\
\hline Prurigo estival (Prurigo de Hutchinson). É um prurigo \\
(lesōes papuloponfosas com ou sem vesiculaçāo) que se \\
relaciona à chegada do verão. Localiza-se, sobretudo, \\
no dorso das mãos, antebraços e pernas, porém, em \\
muitos casos, há lesōes em āreas não expostas, como as \\
nádegas. Alguns autores consideram-no uma \\
variedade de erupção polimorfa luminica (p.412). \\
\hline
\end{tabular}

Nota-se que Azulay não prevê que prurigo estival possa também ser chamado prurigo de verão como o faz Sampaio, mas apresenta outra terminologia (prurigo de Hutchinson) para o termo prurigo estival, o que não acontece em Sampaio. Outra diferença na descrição desse termo em cada obra é que Azulay classifica prurigo estival como um prurigo, e não como erupçāo polimorfa à luz/lumínica.

No VMD, optamos por classificar o termo prurigo estival como um prurigo, deixando claro, assim como o fez Azulay. que alguns autores classificam essa dermatose como uma erupçāo polimorfa luminica, como veremos a seguir: 


VMD
prurigo estival: s m prurigo que atinge pessoas na
primeira década de vida, geralmente no verão. A história
familiar é positiva em metade dos casos. Caracteriza-se
por pápulas e seropápulas, róseas ou eritematosas,
duras, de superficie achatada, com ou sem vesiculação.
A liquenificação e comum. Na face surgem lesões
escoriadas e pápulas de leve coloração amarelada,
semelhando-se à porfiria eritropoiética, e as radiaçōes
monocromáticas em fototestes no espectro do UVB são
normais em metade dos pacientes. Para alguns
especialistas a doença é uma variedade de erupção
polimorfa luminica. Localiza-se na face, no dorso das
mãos, antebraços e pernas, mas há casos em que a
doença aparece em lugares cobertos, como as nádegas.
Outras Designaçōes: prurido de Hutchinson, prurigo
estival ou de verão.

Com base nos dados apresentados, fica claro que, nessa etapa da pesquisa, é de grande importância o papel do terminólogo, que tem de tomar algumas decisōes para organizar os termos em um sistema conceptual único e para redigir as definiçōes. O terminólogo nāo pode simplesmente copiar o sistema conceptual ou as definiçōes de um autor. Sendo assim, procuramos levar em conta a opinião de cada autor, observando a forma como cada um classifica essas dermatoses e, sobretudo, analisando os contextos em que cada fotodermatose aparece.

Muitas vezes, o critério adotado pelo terminólogo para escolher determinada classificação é o da clareza, ou seja, adota-se a classificação do especialista que melhor justifica e define suas escolhas. Desse modo, no VMD, a maioria dos termos-entrada e das definições, no subcampo Fotodermatose, segue o esquema proposto por Azulay. visto que esse autor é o único que apresenta em sua obra um sistema conceptual pronto. Vale lembrar que não descartamos nenhuma informaçāo fornecida pelos outros autores e, sobretudo, consultamos alguns especialistas que concordaram com nossas escolhas. 


\section{Consideraçôes finais}

Por meio do quadro comparativo entre as visões de Azulay \& Azulay e Sampaio \& Rivitti, fica claro que, dependendo da teoria que cada especialista siga, o sistema conceptual, bem como as definiçōes dos termos, apresentam-se de formas diferentes. No meio desse embate encontra-se o terminólogo, que conhece as diferentes posições dos especialistas, dialoga com eles, mas é, afinal, quem toma as decisões, já que suas opções são fundamentadas em razões que foram amadurecendo ao longo do processo de leitura e análise das obras, além da ponderação dos argumentos apresentados pelos especialistas.

Nas definiçōes do VMD, além de constarem vários traços das visões de Azulay \& Azulay. de Sampaio \& Rivitti e até de Bechelli\&Curban, encontram-se também traços da visão do terminólogo, que teve de fazer escolhas entre a classificação de um ou de outro especialista.

A referência a vários especialistas e à qualidade das fontes é de grande importância na elaboração de obras terminográficas. Sendo assim, pode-se dizer que muitas das informações trazidas em tais obras são de responsabilidade não só do terminólogo, mas também dos profissionais da área em questão, já que as visões destes, como já mencionado, acabam impondo caracteristicas ao trabalho terminológico.

\section{BiBLIOGRAFIA:}

AZULAY. R.D., AZULAY D.R. Dermatologia. Rio de Janeiro: Koogan, 1999.

BARROS, L.A. Curso básico de Terminologia. São Paulo:EDUSP, 2004. BECHELLI, L. M., CURBAN. G. V. Compendio de dermatologia. 5. ed. Sāo Paulo: Atheneu, 1988.

CABRÉ, M. T. La terminologia: teoria, metodologia, aplicaciones. Barcelona: Editorial Antátida/Empúries, 1993.

DUBUC. R. Manuel pratique de terminologie. 2. ed. Québec: Linguatech. 1985. 
ORGANISATION INTERNATIONALE DE NORMALISATION. Terminologie - Vocabulaire, (Norme Internationale ISO 1087: 1990). Genebra: ISO, 1990.

PAVEL. Silvia; NOLET, Diane. Manual de terminologia. Disponivel em: www.translationbureau.gc.ca. Acesso em: 01 set. 2002.

RONDEAU, G. Introduction à la terminologie. 2. ed. Québec: Gaëtan Morin, 1984.

SAMPAIO, S. A. P., CASTRO, R. M., RIVITTI, E. A. Dermatologia Básica. 2. ed. São Paulo: Artes Médicas, 2001. 